"Interstrand interactions on DNA duplexes modified by TTF units at the 3' or 5'-ends". PérezRentero, S., Gállego, I., Somoza, A., Ferreira, R., Janousek, J., Belohradsky, M., Stara, I., Stary, I., Eritja, R. RSC Adv., $\underline{2}$, 4069-4071 (2012).

\title{
Interstrand interactions on DNA duplexes modified by TTF units at the 3' or 5'-ends
}

\author{
Sónia Pérez-Rentero,,${ }^{a}$ Isaac Gállego,${ }^{a}$ Álvaro Somoza, ${ }^{b}$ Rubén Ferreira,${ }^{a}$ Jiř́ Janoušek,${ }^{c}$ \\ Martin Bělohradský, ${ }^{c}$ Irena G. Stará, ${ }^{c}$ Ivo Starý ${ }^{c}$ and Ramon Eritja*a
}

${ }^{a}$ Institute for Research in Biomedicine (IRB Barcelona), IQAC-CSIC,CIBER-BBN, Baldiri Reixac 10, 08028 Barcelona, Spain. Fax: 3493 2049942; Tel: 3493 4039942; E-mail: recgma@cid.csic.es

${ }^{5} I M D E A-N a n o c i e n c i a$, E-28049 Madrid, Spain;

'Institute of Organic Chemistry and Biochemistry (IOCB), v.v.i. Academy of Sciences of the Czech Republic, Flemingovo năm. 2, 16610 Prague 6, Czech Republic.

Short DNA duplexes carrying TTF units at the same termini exhibit a high increase in melting temperature. When both TTF units were on opposite termini salt-dependent aggregation is observed yielding well defined spherical DNA supramolecular structures .

Tetrathiafulvalene (TTF) derivatives are strong electron-donating molecules which have been used for the development of organic conducting materials ${ }^{1}$ as well as building blocks in supramolecular chemistry. ${ }^{2}$ TTFs are frequently used as donor units in donor-acceptor (D-A) assemblies in molecular electronics. ${ }^{3}$ Upon oxidation, TTF derivatives are capable of forming stable cation radical and dication species. ${ }^{1}$ The incorporation of aliphatic and amphiphilic groups peripheral to the TTF unit allows for the generation of ordered arrays ${ }^{4,5}$ as well as oxidation-responsive organogels. ${ }^{6,7}$

We are interested in conjugation of oligonucleotides with functional $\pi$-electron systems as their $\pi-\pi$ or D-A interactions may provide additional binding energies without perturbing the specific recognition with the complementary sequences. To this end we combine the base-pairing system of DNA with the properties of TTF in order to study the properties of the resulting hybrid systems. Previous to this work, the synthesis of a small RNA oligonucleotide carrying a uridine derivative with TTF was described. ${ }^{8}$ Later, TTF-labelled nucleotide triphosphates were incorporated into DNA by primer extension with DNA polymerases although low efficiency of their incorporation was reported. ${ }^{9}$ Recently, the controlled incorporation of TTF units into internal positions of oligonucleotides was published. ${ }^{10,11}$ Fluorescence quenching in TTF/pyrene modified heteroduplexes was observed $^{10}$ as well as the electrochemical properties of TTF-oligonucleotides were reported ${ }^{11}$ indicating that the properties of TTF are preserved when inserted in oligonucleotides.

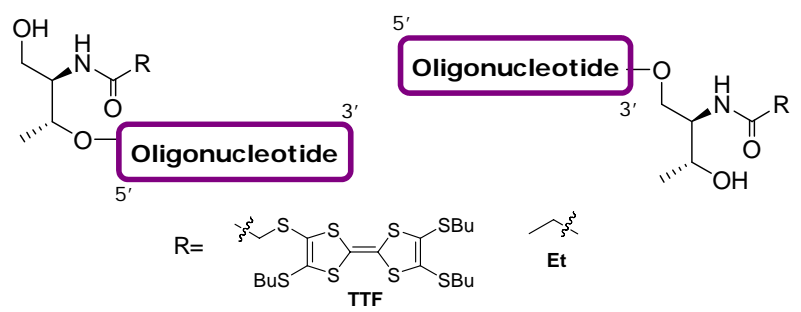

Based on these reports, we synthesized several oligonucleotides carrying a TTF unit functionalized with three aliphatic S-butyl groups at either 3' or 5'-end of the oligonucleotide. Their complementary oligonucleotide sequences carrying TTF groups were used to form DNA duplexes with TTF groups at the same 
or opposite termini of the duplex. The relative thermal stability was analyzed demonstrating a distinct behavior of the TTF oligonucleotide conjugates that is in agreement with the supramolecular properties of both TTF and oligonucleotides and is regulated by the salt concentration.

Table 1. Oligonucleotide sequences prepared in this study

\begin{tabular}{lll} 
Oligonucleotide & \multicolumn{1}{c}{ Sequence $\left(5^{\prime}-3^{\prime}\right)^{*}$} \\
$\mathbf{1}$ & CCAATTGG \\
$\mathbf{2}$ & CCAATTGG-TTF \\
$\mathbf{3}$ & TAGAGGCTCCATTGC \\
$\mathbf{4}$ & GCAATGGAGCCTCTA \\
& $\mathbf{5}$ & TAGAGGCTCCATTGC-TTF \\
& $\mathbf{6}$ & GCAATGGAGCCTCTA-TTF \\
& $\mathbf{7}$ & TTF-TAGAGGCTCCATTGC \\
* TTF: tetrathiafulvalene, Et: ethyl & $\mathbf{8}$ & TTF-GCAATGGAGCCTCTA \\
& $\mathbf{9}$ & TAGAGGCTCCATTGC-Et
\end{tabular}

L-threoninol was selected as a linker to incorporate the TTF moiety into DNA as well as an ethyl group as non- $\pi$-electron system for the comparison purposes. Threoninol has been used previously to introduce several units such as Methyl Red moieties, ${ }^{12}$ photoactive azobenzenes, ${ }^{13}$ or TTF,${ }^{11}$ into oligonucleotides.

The synthesis of the threoninol derivatives is described in the supporting section (SI). Tetrathio-substituted TTF equipped with a carboxylic acid functional group was prepared analogously to the literature procedure. ${ }^{14}$ Oligonucleotide sequences shown in Table 1 were prepared using a DNA synthesizer. Oligonucleotides $\mathbf{1}$ and 2 are self-complementary octamers without or with a single TTF unit at the 3'-end, respectively. Oligonucleotides 3 and $\mathbf{4}$ are pentadecamers comprising complementary sequences. Oligonucleotides 5-8 are derivatives of $\mathbf{3}$ and $\mathbf{4}$ modified by a single TTF unit that is attached at the 3' or 5'-end. Oligonucleotide 9 is the derivative of $\mathbf{3}$ carrying one ethyl group at the 3'-end. In general, oligonucleotides were obtained in good yields but those carrying the TTF unit were not entirely stable in the presence of ammonia. Such a partial degradation was reduced by shortening the period of deprotection $\left(4 \mathrm{~h}\right.$ at $\left.55{ }^{\circ} \mathrm{C}\right)$. The desired oligonucleotides were easily separated from degradation products by HPLC (SI). We also observed degradation during the phosphoramidite coupling to attach the TTF unit at the 5'-end. This instability of the TTF-modified compounds occurred namely when the reaction period was prolonged from $30 \mathrm{~s}$ to $10 \mathrm{~min}$. Accordingly, shorter coupling times were used. Mass spectrometry analyses of the major HPLC peaks were consistent with the desired structures (SI).

Figure 1. The denaturation curves of the self-complementary octamers 1 and 2. A) Melting profile of the octamer 1 at $1 \mathrm{M} \mathrm{NaCl}\left(\mathrm{T}_{\mathrm{m}}=36.1{ }^{\circ} \mathrm{C}\right)$. B) The TTF-oligonucleotide 2 at different $\mathrm{NaCl}$ concentrations $\left(50 \mathrm{mM}\right.$ : $\mathrm{T}_{\mathrm{m}}=27.3{ }^{\circ} \mathrm{C} ; 100$ $\mathrm{mM}: \mathrm{T}_{\mathrm{m}}=33.8^{\circ} \mathrm{C} ; 200 \mathrm{mM}: \mathrm{T}_{\mathrm{m}}=35.8^{\circ} \mathrm{C}$ ). C) Absorption spectra at $10^{\circ} \mathrm{C}$ and $80^{\circ} \mathrm{C}$ of the TTF-oligonucleotide 2 at $50 \mathrm{mM} \mathrm{NaCl}$. D) the same as in (C) but at $1 \mathrm{M} \mathrm{NaCl}$.

A)

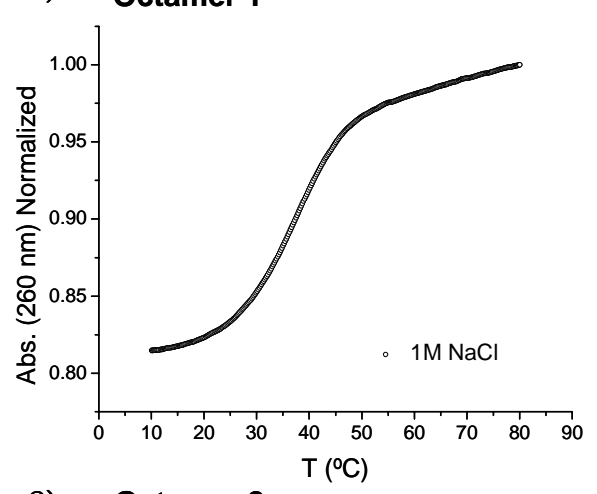

C) Octamer 2

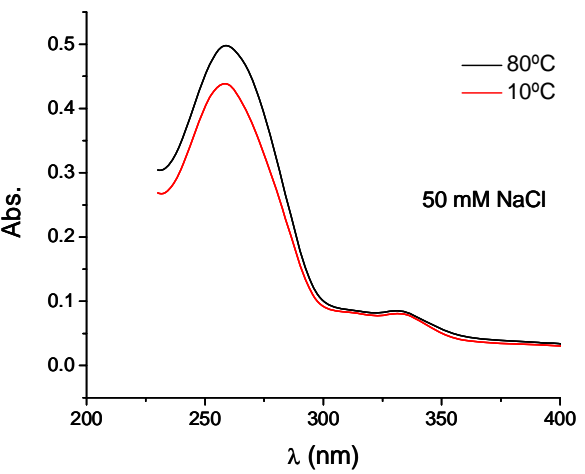

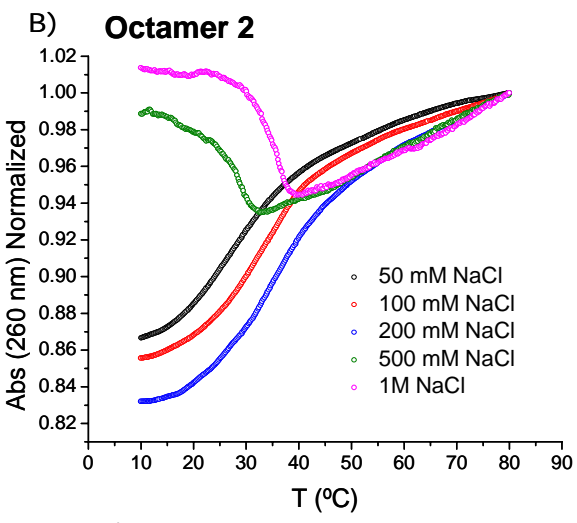

D) Octamer 2

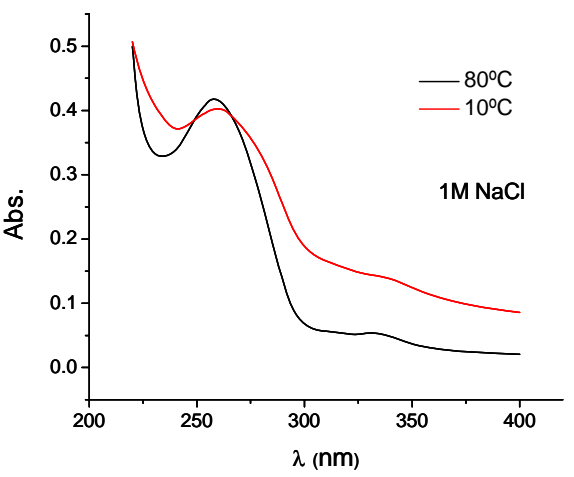


Thermal denaturation curves of the duplexes formed by the self-complementary octamer $\mathbf{1}$ or $\mathbf{2}$ were recorded at the high salt concentration $(1 \mathrm{M} \mathrm{NaCl}, 10 \mathrm{mM}$ sodium phosphate at $\mathrm{pH}$, Figure 1). The unmodified octamer 1 exhibited a normal sigmoidal curve with hyperchromicity at $260 \mathrm{~nm}$ giving a melting temperature of $\mathrm{T}_{\mathrm{m}}=36.1{ }^{\circ} \mathrm{C}$ (Figure 1A). On the contrary, the octamer 2 showed an unusual denaturation curve (Figure 1B). The small increase in absorbance at $260 \mathrm{~nm}$ was due to an anomalous UV spectrum of the octamer 2 at low temperature $\left(10^{\circ} \mathrm{C}\right.$, Figure 1D). The absorption bands were broad showing light scattering due to the formation of aggregates. This effect disappeared upon heating to $80{ }^{\circ} \mathrm{C}$ (Figure 1D). By lowering the salt concentration from $1 \mathrm{M}$ to $50 \mathrm{mM} \mathrm{NaCl}$, the melting curves returned to the standard shapes below $200 \mathrm{mM}$ $\mathrm{NaCl}$ (Figure 1B). The UV spectra at low temperatures and the low salt concentration showed no light scattering (Figure 1C).

Since the larger changes in the absorbance spectrum of the octamer 2 at the $1 \mathrm{M} \mathrm{NaCl}$ concentration were observed at $\lambda \geq 300 \mathrm{~nm}$, the melting experiments were also recorded at $300 \mathrm{~nm}$ to monitor the aggregation process using two different gradients of temperature $\left(1{ }^{\circ} \mathrm{C} / \mathrm{min}\right.$ and $\left.0.1{ }^{\circ} \mathrm{C} / \mathrm{min}\right)$. A large hysteresis was observed (Figure S3), indicating that the dissociation of the aggregate was faster than the formation of the aggregate. A similar experiment was performed with a $50 \mathrm{mM} \mathrm{NaCl}, 10 \mathrm{mM}$ sodium cacodylate and $10 \mathrm{mM}$ $\mathrm{MgCl}_{2}$ buffer $(\mathrm{pH}=7)$ using a $1{ }^{\circ} \mathrm{C} / \mathrm{min}$ gradient (Figure $\mathrm{S} 3 \mathrm{~B}$ ). Compared with the melting profile measured with the $1 \mathrm{M} \mathrm{NaCl}$ solution, we can conclude that magnesium ions are promoting the aggregation more effectively than sodium ions as only the $10 \mathrm{mM}$ magnesium concentration is needed to observe aggregation (Figure S3, Table S1).

The formation of the TTF-oligonucleotide aggregates at the high salt concentration and low temperature was confirmed by dynamic light scattering (DLS) and transmission electron microscopy (TEM). The mean size obtained at $15^{\circ} \mathrm{C}$ by DLS with $1 \mathrm{M} \mathrm{NaCl}$ solutions of octamer 2 after incubation at $4^{\circ} \mathrm{C}$ for $24 \mathrm{~h}$ and $48 \mathrm{~h}$ were similar (Figure S10). The averaged diameter after $24 \mathrm{~h}$ was $216 \pm 32 \mathrm{~nm}$ with an averaged polydispersity index (PDI) of $0.23 \pm 0.04$ and after $48 \mathrm{~h}$ was $221 \pm 31 \mathrm{~nm}$ with an averaged PDI of $0.24 \pm 0.03$. Heating at $80{ }^{\circ} \mathrm{C}$ or lowering the salt concentration to $50 \mathrm{mM} \mathrm{NaCl}$ induced a large reduction of the particle size to $10-15 \mathrm{~nm}$ with an increase of the PDI. TEM visualization of the octamer 2 formed at $1 \mathrm{M} \mathrm{NaCl}$ at $24 \mathrm{~h}$ and $48 \mathrm{~h}$ showed that the aggregates are mainly spherical structures of sizes ranging from 90 to $210 \mathrm{~nm}$ with a mean diameter of about $150 \mathrm{~nm}$ (Figure 2; also see Figure S11). The difference in size obtained from both techniques could be explained by the drying process needed for TEM visualisation (see SI).

Figure 2. TEM micrograph of the DNA spherical structures of the self-complementary octamer 2. The structures were imaged after $48 \mathrm{~h}$ of incubation at $4{ }^{\circ} \mathrm{C}$, adsorved over the grid and stained with uranyl acetate.

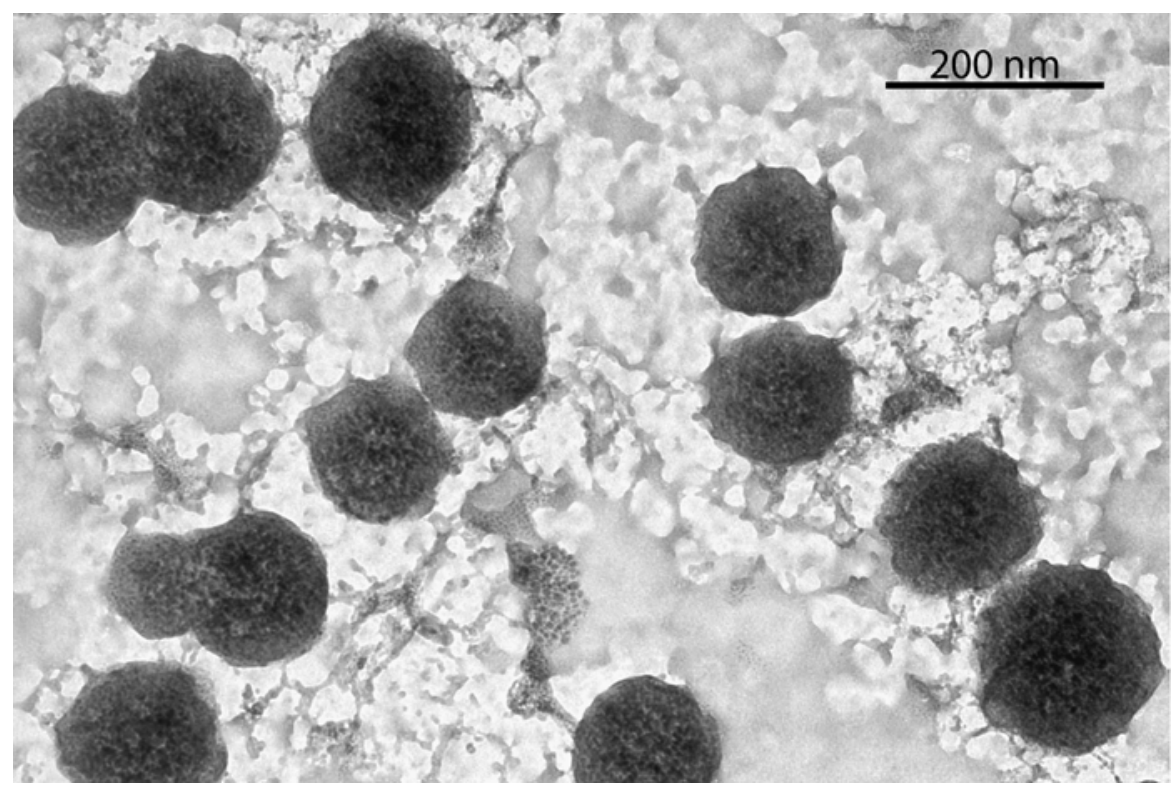


Next, melting experiments with duplexes constituted by the oligonucleotides 3-8, which are longer and non self-complementary, were performed at high and low salt concentrations (Table 2, Figures S6-S9). At the 50 $\mathrm{mM} \mathrm{NaCl}$ concentration, the unmodified duplex $3+4$ melted at $55.8{ }^{\circ} \mathrm{C}$. Duplexes having a TTF unit such as $\mathbf{3}+\mathbf{6}$ and $\mathbf{5}+\mathbf{4}$ showed higher $\mathrm{T}_{\mathrm{m}}$ than unmodified duplex $\mathbf{3}+\mathbf{4}\left(\Delta \mathrm{T}_{\mathrm{m}} 2.8\right.$ and 1.4$)$. The duplexes $\mathbf{5}+\mathbf{6}$ and $\mathbf{7}+\mathbf{8}$ having two TTF units, each one at the different ends of the duplex, exhibit a higher stability. This is in agreement with the additive effect of two TTF units $\left(\Delta \mathrm{T}_{\mathrm{m}} 3.1\right.$ and 3.4). Surprisingly, the duplexes $7+\mathbf{6}$ and $\mathbf{5}+\mathbf{8}$ having two TTF units at the same end of the duplex had an extraordinary high thermal stability $\left(\Delta \mathrm{T}_{\mathrm{m}} 11.4\right.$ and 10.9). Such a high increase in $T_{m}$ is indicative for a strong intermolecular interaction between the TTF moieties.

Table 2. The melting experiments with duplexes carrying the TTF unit(s).

\begin{tabular}{|c|c|c|}
\hline Oligonucleotides & $\begin{array}{c}\operatorname{Tm}\left({ }^{\circ} \mathrm{C}\right) \\
(50 \mathrm{mM} \mathrm{NaCl}) \\
\end{array}$ & $\begin{array}{c}\operatorname{Tm}\left({ }^{\circ} \mathrm{C}\right) \\
(1 \mathrm{M} \mathrm{NaCl})\end{array}$ \\
\hline $3+4 \quad \Longleftrightarrow$ & 55.8 & 67.4 \\
\hline TTF & -- & Aggr. ${ }^{[a]}$ \\
\hline $3+6 \quad$ TTF & $58.6(+2.8)^{[\mathrm{b}]}$ & $69.5(+2.1)^{[\mathrm{b}]}$ \\
\hline $5+4 \quad \rightleftarrows$ TTF & $57.2(+1.4)$ & $68.2(+0.8)$ \\
\hline $5+6 \underset{\mathrm{TTF}}{\rightleftarrows} \rightleftarrows \mathrm{TTF}$ & $58.9(+3.1)$ & Aggr. \\
\hline $7+8 \quad \mathrm{TTF} \rightleftarrows$ & $59.2(+3.4)$ & Aggr. \\
\hline $7+6 \quad \stackrel{\text { TTF }}{\text { TTF }}$ & $67.2(+11.4)$ & Aggr. / $81.6(+14.2)$ \\
\hline $5+8 \quad \Longleftrightarrow_{\mathrm{TTF}}^{\mathrm{TTF}}$ & $66.7(+10.9)$ & $86.2(+18.8)$ \\
\hline $9+6 \underset{\mathrm{TTF}}{\rightleftarrows}$ & $56.9(+1.1)$ & $68.7(+1.3)$ \\
\hline $9+8 \quad \Longrightarrow \mathrm{Tt}$ & $57.1(+1.3)$ & $68.1(+0.7)$ \\
\hline
\end{tabular}

[a] Aggr. Indicates that a broad UV spectrum with a large light scattering was observed. [b] The data in parentheses show the difference in Tm between the non modified duplex and modified duplexes under otherwise the same conditions. The arrows indicate the oligonucleotide orientation $5^{\prime} \rightarrow 3$ '.

A similar behavior was also observed at the $1 \mathrm{M} \mathrm{NaCl}$ concentration when an aggregation could also be monitored. As for the octamer $\mathbf{2}$, the aggregation was mainly seen at the duplexes $\mathbf{5}+\mathbf{6}$ and $\mathbf{7}+\mathbf{8}$ having two TTF units at the different ends of the duplex. This indicated an intermolecular interaction between TTFs, which resulted in the aggregation rather than the duplex stabilization. In addition, the aggregation was also observed at the single-strand TTF oligonucleotide 6 and at the pair $6+7$ (Figures S5-S7). In the latter case, the duplex-torandom coil transition was so high that it could be observed after the aggregation process and $\mathrm{T}_{\mathrm{m}}$ was measured. At $1 \mathrm{M} \mathrm{NaCl}$ duplexes $7+6$ and $\mathbf{5}+\mathbf{8}$ had the highest thermal stability $\left(\Delta \mathrm{T}_{\mathrm{m}} 14.2\right.$ and 18.8$)$. As expected, the duplex carrying the ethyl group $(\mathbf{9}+\mathbf{6}$ and $\mathbf{9 + 8})$ showed similar melting temperatures as compared with the unmodified duplex $(3+4)$.

In summary, we described a striking effect of a TTF moiety linked to the 5' or 3'-end of oligonucleotides on the stability of the corresponding DNA duplexes. If two TTF units are attached, then either the aggregation or strong duplex stabilization or both can be observed depending on the relative position of the TTF units within the duplex (being bound to the same end or to the opposite ones) and salt concentration. Such remarkable changes in assembly properties of the TTF-modified oligonucleotides have not yet been reported. ${ }^{15}$ It is worth mention that salt-induced aggregation of DNA-porphyrin conjugates have been observed by long-ranged exciton-coupled circular dichroism. ${ }^{16}$ Moreover, DNA micelles can be obtained with lipid-DNA conjugates with increased cell permeability. ${ }^{17}$ The strong oligonucleotide duplex stabilization and the salt-induced formation of aggregates in diluted solutions of TTF-DNA conjugates may provide a basis for the development of applications like the design of novel delivery systems or the development of salt-responsive self-assembled materials.

Acknowledgments. This research was supported by the European Commission under Grant No. FP7-FUNMOL 213382, by the Spanish Ministry of Education (CTQ2010-20541), the Generalitat de Catalunya (2009/SGR/208), the Czech Science Foundation (P207/10/2214) and the Institute of Organic Chemistry and Biochemistry AS CR (this work is part of the Research Project Z4 055 0506). Dr. Radek Pohl is acknowledged for the NMR spectra measurement as well as the electron cryo-microscopy unit from CCiT of University of 
Barcelona for the use of the EM facility.

\section{Notes and references}

1 J. Yamada and T. Sugimoto, in TTF Chemistry, Fundamentals and applications of tetrathiafulvalene, Springer, Berlin 2004.

2 J. L. Segura and N. Martin, Angew. Chem. Int. Ed., 2001, 40, 1372.

3 M. Bendikov, F. Wudl and D. F. Perepichka, Chem. Rev., 2004, 104, 4891.

4 M. M. S. Abdel-Mottaleb, E. Gomar-Nadal, M. Suri, H. Uji-I, W. Mamdouh, J. Veciana, V. Lemaur, C. Rovira, J. Cornil, R. Lazzaroni, D. B. Amabilino, S. De Feyter and F. C. De Schryver, J. Mater. Chem., 2005, 15, 4601 .

5 D. R. Talham, Chem. Rev., 2004, 104, 5479.

6 J. Puigmartí, V. Laukhin, A. V. del Pino, J. Vidal-Gancedo, C. Rovira, E. Laukhina and D. B. Amabilino, Angew. Chem. Int. Ed. ,2007, 46, 238.

7 C. Wang, D. Zhang and D. Zhu, J. Am. Chem. Soc., 2005, 127, 16372.

8 O. Neilands, V. Liepinsh and B. Turovska, Org. Lett., 1999, 1, 2065.

9 J. Riedl, P. Horáková, P. Sebest, R. Pohl, L. Havran, M. Fojta and M. Hocek, Eur. J. Org. Chem., 2009,3519

10 N. Bouquin, V. L. Malinovskii, X. Guégano, S. X. Liu, S. Decurtins and R. Häner, Chem. Eur. J., $2008,14,5732$.

11 M. Schnippering, A. Zahn, S. X. Liu, C. Leumann and S. Decurtins Chem. Comm., 2009, 5552.

12 H. Asanuma, K. Shirasuka, T. Takarada, H. Kashida and M. Komiyama, J. Am. Chem. Soc., 2003, $125,2217$.

13 H. Kashida, X. Liang, and H. Asanuma, Curr. Org. Chem., 2009, 13, 1065.

14 A. Zhao, B.T.; Blesa, M.J.; Le Derfa, F.; Caneveta, D.; Benhaoua, C.; Mazari, M.; Allaina, M.; Sallé, M. Tetrahedron 2007, 63, 10768

15 J. Tuma, W. H. Connors, D. H. Stitelman, and C. Richert, J. Am. Chem. Soc., 2002, 124, 4236.

16. A. Mammana, G. Pescitelli, T. Asakawa, S. Jockusch, A. G. Petrovic, R. R. Monaco, R. Purello, N. J. Turro, K. Nakanishi, G. A. Ellestad, M. Balaz and N. Berova, Chem. Eur. J., 2009, 15, 11853.

17. H. Liu, Z. Zhu, H. Kang, Y. Wu, K. Stefan, W. Tan, Chem. Eur. J., 2010, 16, 3791. 